\title{
Administration of metformin in clinical medicine; an updated mini-review on current findings
}

\author{
Mahrang Hedaiaty* \\ Forensic Medicine- Legal Medicine Organization, Tehran, Iran
}

\section{A R T I C L E I N F 0}

Article Type:

Mini-Review

\section{Article History:}

Received: 20 October 2017

Accepted: 4 January 2018

ePublished: 20 January 2018

\section{Keywords:}

Lactic acidosis

Renal failure

Metformin

Nephrotoxicity

Acute kidney injury

Mitochondrial dysfunction

\begin{abstract}
A B S T RACT
Metformin is in the biguanide class that has been considered as the treatment for insulin resistance diabetes and polycystic ovarian disease. Many mechanisms have been suggested for it such as inhibition of the mitochondrial respiratory chain and mitochondrial glycerophosphate dehydrogenase, activation of adenosine monophosphate-activated protein kinase, inhibition of glucagon-induced elevation of cyclic adenosine monophosphate with reduced activation of protein kinase $\mathrm{A}$, an effect on gut microbiota and activation of adenosine monophosphateactivated protein kinase. Metformin is a suppressor for transforming growth factor- $\beta 1$ via directly binding and interact with transforming growth factor- $\beta 1$ receptor. Lactic acidosis is one of the adverse and noxious effects of metformin. Nowadays, metformin has an important role in inflammation pathways and antioxidant pathways that can prevent or decrease kidney fibrosis, cardiac remodeling in hypertensive heart disease, and cell death in cerebral ischemia, kidney crystal formation, immunological diseases and cancer. Although there has been strong evidence for the potential harm caused by metformin, several studies have shown beneficial effects for it. Hence, it is necessary to revision and modification in contraindications for prescription of this drug.
\end{abstract}

Implication for health policy/practice/research/medical education:

Metformin has an important role in inflammation and antioxidant pathways that can prevent or decrease kidney fibrosis, cardiac remodeling in hypertensive heart disease, and cell death in cerebral ischemia, kidney crystal formation, immunological diseases and cancer.

Please cite this paper as: Hedaiaty M. Administration of metformin in clinical medicine; an updated mini-review on current findings. J Nephropharmacol. 2017;7(2):61-65.

\section{Introduction}

Metformin (1, 1-dimethylbiguanide hydrochloride) is in the biguanide class that was discovered in 1922 and introduced as a medication in 1957 (1). First, it was derived from the lilac Gallegos officinalis (2).

Metformin hydrochloride (Glucophage) is formed of a white to off-white crystalline compound with a molecular weight of 165.63. Metformin hydrochloride is soluble in water but is insoluble in acetone, ether and chloroform. It has been considered as first-line therapy for insulin resistance diabetes (type 2 diabetes) as a monotherapy and combined with other medication such as pioglitazone, vildagliptin and sitagliptin (3). It does not induce hypoglycemia (4). It is also used in type 1 diabetes in conjunction with insulin therapy (5). In addition, metformin is used in the treatment of polycystic ovary syndrome (6).

Many physicians believe that metformin prescription should be stopped with the presentation of severe kidney disease (7) or diabetic ketoacidosis state (8) but there is novel information about its beneficial effects.

There are recommendations that metformin is contraindicated in patients with renal dysfunction, abnormal creatinine clearance (9), conditions such as cardiovascular shock, septicemia and metabolic acidosis (10).

\section{Materials and Methods}

For this paper, we used a variety of sources including Web of Science, PubMed, EBSCO, Embase, Scopus and directory of open access journals (DOAJ). The search was performed by using combinations of the following key words and or their equivalents; chronic kidney disease, diabetes mellitus, hypertension, acute kidney injury, type 2 diabetes, end-stage renal disease, kidney, lactic acidosis, renal failure, metformin, nephrotoxicity, mitochondrial dysfunction, metformin-associated lactic acidosis, glucose transporter 4, adenosine monophosphate-activated 
protein kinase and antioxidants.

How does metformin act in the body?

The action mechanism of metformin is incompletely understood and many mechanisms have been suggested for it. Metformin prevents the production of glucose in the liver, reduces the amount of sugar absorbed by the intestines and improves the body's sensitivity towards insulin. Furthermore, the molecular mechanism of metformin is not fully understood (11). Researchers have been proposed the following potential mechanisms; inhibition of the mitochondrial respiratory chain and mitochondrial glycerophosphate dehydrogenase (12), activation of adenosine monophosphate -activated protein kinase (13), inhibition of glucagon-induced elevation of cyclic adenosine monophosphate with reduced activation of protein kinase A (14) and an effect on gut microbiota (15).

The drug has an inhibitory effect on the production of glucose by activation of adenosine monophosphateactivated protein kinase (AMPK) that plays an important role in the metabolism of glucose, insulin signaling, and whole body energy balance in liver cells (16). Moreover, metformin increases AMPK activity in skeletal muscle that causes glucose transporter 4 (GLUT4) placements to the plasma membrane, causing in insulin-independent glucose uptake (17).

Metformin may antagonize the action of glucagon through an effect on glucagon-like peptide-1 secretion and reduce fasting glucose levels (18).

In addition to increasing insulin sensitivity, metformin decreases insulin-induced suppression of fatty acid oxidation (19) and diminutions absorption of glucose from the gastrointestinal tract (20).

Metformin may be mediated by protein kinase $\mathrm{C}$ and mitogen-activated protein kinase that is a signaling molecule to involve in multiple cellular processes such as cell proliferation and cell growth (21).

Metformin is recently known as a suppressor for transforming growth factor- $\beta_{1}$ via directly binding and interact with transforming growth factor- $\beta_{1}$ receptor (22). Transforming growth factor- $\beta_{1}$ is involved in the progression of numerous diseases such as cardiovascular, fibrotic and immunological diseases and cancer (22).

\footnotetext{
Absorption and bioavailability

Oral metformin bioavailability is $50 \%-60 \%$ under fasting conditions. Peak plasma concentrations are reached within 1-3 hours of ingestion immediate-release the drug and 4-8 hours with extended-release formulations. The plasma protein binding of metformin is very small, but its volume of distribution is very high $(654 \pm 358 \mathrm{~L}$ after a single dose) and distributed to red blood cells. The steady state plasma concentrations of metformin are usually reached less than $1 \mu \mathrm{g} / \mathrm{mL}$ within 24 to 48 hours. Metformin is not metabolized and cleared by tubular secretion and excreted unchanged in the urine.
}

The adverse and noxious effects

The adverse effect of metformin consumption is gastrointestinal irritation such as dyspepsia, nausea, vomiting, diarrhea, cramps, and increased flatulence diarrhea that occurs in up to $30 \%$ of patients (23). Symptoms of metformin overdose may be nonspecific and include malaise, abdominal pain, nausea, vomiting, myalgia and dizziness (23). The severe clinical manifestation of this poisoning is metformin-associated metabolic acidosis (MALA) with hyperlactatemia (24). Although hypoglycemia is not common event in metformin toxicity process, there are some cases that reported previously (25).

The studies have reported a reduced serum thyroidstimulating hormone (TSH) levels at the initiation of metformin administration (26). According to another study metformin-induced TSH suppression was not associated with cardiac effects (27). However other researchers have not found significant changes in thyroid function tests and serum levels of TSH in euthyroid patients with receiving metformin (28).

\section{Metformin-associated lactic acidosis}

The overdose of this medication is commonly known to cause MALA (29). The frequency of MALA occurrence has been reported to be $0.7 \%$ in poly-pharmacy overdoses to $9.1 \%$ in mono-overdose (30).

The mortality rate of the condition has been reported to be between $3.5 \%-22.7 \%$ in accidental and 25\%-83\% in intentional overdoses in different studies. However, MALA may be considered as a very rare complication of chronic metformin therapy, with an incidence of around 5 cases per 100000 patient-years (24).

A systematic review showed that MALA is not common (31). It is mainly caused due to suppression of the pyruvate decarboxylase enzyme (32), inhibition of gluconeogenesis in hepatic cells (33) and inhibition of plasma cell differentiation antigen $(34,35)$.

Hyperlactatemia occurs in various diseases, but in this condition, it can be present in the absence of acidosis. Lactic acid does not produce a net increase in hydrogen ion concentration unless there is associated impairment of oxidative metabolism. Impaired oxidative metabolism leads to an increase in hydrogen ion production through the hydrolysis of adenosine triphosphate. In an animal model research, mitochondrial dysfunction and inhibition of oxygen consumption occurred due to metformin overdose. Additionally in another study, metformin inhibits both hepatic lactate uptake and conversion of lactate to glucose in isolated perfused rat liver.

Symptoms may be nonspecific and include confusion, mental status depression, hypothermia, respiratory insufficiency, hypotension and blindness. Patients may be developing renal failure or other serious comorbid conditions and need to the administration of sodium bicarbonate and further management with hemodialysis or other techniques of extracorporeal removal. Fatalities following poisoning are rare, but may occur. A 
review study did not find deaths in cases with a serum $\mathrm{pH}$ greater than 6.9, a peak serum lactate concentration less than $25 \mathrm{mmol} / \mathrm{L}$ or a peak serum metformin concentration less than $50 \mu \mathrm{g} / \mathrm{mL}$. Moreover, serum metformin concentrations could be obtained as a diagnostic aid, but these did not correlate with the clinical condition in both the acute overdose setting and the setting of therapeutic metformin administration.

Notably, there have been millions of metformin user for many years, numerous of them with serum creatinine values nearly $1.5 \mathrm{mg} / \mathrm{dL}$ with estimated glomerular filtration rates lesser than $60 \mathrm{~mL} / \mathrm{min} / 1.73 \mathrm{~m}^{2}$ who have not developed lactic acidosis.

The role of metformin in the development of MALA in the setting of acute renal failure is debated. Several experiments suggested that this drug can be nephrotoxic. A systematic review of controlled trials suggested metformin is not associated with any measurable harm in people and it may reduce mortality in comparison with other ant diabetic agents. However, according to other studies, the risks of MALA increase in patients with some conditions including kidney disorders, liver disease(for example; alcoholic fatty liver disease), lung disease and heart failure (particularly; acute congestive heart failure). A review of intentional and accidental metformin overdoses described that MALA was rare although the elderly seemed to be at greater risk. In a cohort study including cases with diabetes that developed acute renal failure, the administration of metformin was associated with MALA and worsening of renal function. When impaired kidney function is present, clearance of lactate and metformin is reduced. Hence, renal function is recommended to assess before administration of metformin and to temporarily intercept before any radiographic study with iodinated contrast agents. Moreover, it is better to measure lactate levels for patients presenting under critical conditions in a emergency department or even in a clinic to be able to recognize and treat MALA in a timely manner.

\section{The novel beneficial effects}

Although there have been a number of surveys on the potential harm caused by metformin, some studies have investigated its beneficial effects.

In addition to treatment of diabetes mellitus (36) and polycystic ovarian disease (6), metformin may prevent kidney fibrosis (37). Tubulointerstitial fibrosis is the unavoidable sequel to chronic kidney disease regardless of the primary underlying causes (38). Tubular epithelial cells, myofibroblasts and endothelial cells play important roles in this process (38). Injured tubular epithelial cells suppress fatty acid oxidation with effect on the regeneration capacity and fibrogenesis during metabolic rearrangements (39). Immune cells in kidney such as macrophages, lymphocytes, mast cells and dendritic cells mediate inflammation and immune response (40). The in-vitro and in-vivo model study showed that metformin exerts anti-fibrotic effects in aldosterone on the heart (41).
In description, metformin might be inhibited aldosterone which induced activation, migration and proliferation of cardiac fibroblasts and inhibited AMPK phosphorylation as well as induced protein phosphatase magnesium dependent 1A (PPM1A) activation and collagen expression (41). As a further matter, Mummidi and Das highlighted that metformin inhibited pro-inflammatory cytokine expression and potentially inhibited effects of spironolactone on aldosterone-induced collagen expressions (41). Thus, metformin can potentially reduce adverse cardiac remodeling in hypertensive heart disease (41). Saeedi et al also demonstrated that metformin inhibited inflammatory cytokines, oxidative stress and necrosis by acetaminophen-induced hepatotoxicity in mice through hepatocytes protection and an antiinflammation and antioxidative mechanism (42). There is clear evidence that metformin can decrease cell death in cerebral ischemia (43). In recent studies metformin was able to conduct AMPK in the experimental cerebral ischemia, suppress inflammation pathways, protect cells through antioxidant pathways throw increased the level of catalase activities and glutathione (43). Moreover, the drug may increase lipid peroxidation, DNA degradation and monoamine oxidase activity. Additionally, metformin can stabilize and normalize the membrane functions via reduction in membrane fluidity, sodium-potassium pump, antioxidant enzymes activities (44).

Other beneficial effect of metformin, according to a rat study, is the prevention of renal tubular epithelium cell injury associated to oxalate and stone by inhibition of kidney crystal formation via renal tubular cell protection and anti-oxidative effects (45).

Researchers showed that metformin may rescue neurons from Huntington's disease by acting on cell metabolism at multiple levels throw activation of AMPK, prevention of mitochondrial membrane depolarization and modulation of the disturbed mitochondrial dynamics in brain (46). Lin et al also showed that activation of AMPK via metformin has been associated with reducing the oxidative stress and neurodegeneration in human neural stem cells (47). Likewise, Bibi et al demonstrated that metformin treated subjects has beneficial effects against apoptotic neurodegeneration in $\mathrm{HCN}-2$ neuronal cells and seizures (48).

Metformin may protect auditory hair cells from apoptotic cell death by reduction of intracellular reactive oxygen species (49).

Metformin also has inhibitory effects on various cancer types in mouse models (50). In addition, cancer incidence and cancer-related mortality decreased in patients with type 2 diabetes treated with metformin in epidemiological studies (51).

\section{Conclusion}

Although there has been strong evidence for the potential harm caused by metformin, some studies have showed beneficial effects for it. Hence, it is necessary to revision 
and modification in contraindication for prescription of this drug.

Authors' contribution

$\mathrm{MH}$ is the single author of the paper.

Conflicts of interest

The author declares no conflict of interest.

Ethical considerations

Ethical issues (including plagiarism, data fabrication, double publication) have been completely observed by the author.

\section{Funding/Support}

None.

\section{References}

1. Bailey CJ. Metformin:historical overview. Diabetologia. 2017;60:1566-1576. doi: 10.1007/s00125-017-4318-z.

2. Bailey CJ, Day C:Metformin:its botanical background. Pract Diab Int. 2004;21:115-117.

3. Craddy P, Palin HJ, Johnson KI. Comparative effectiveness of dipeptidylpeptidase- 4 inhibitors in type 2 diabetes:a systematic review and mixed treatment comparison. Diabetes Ther. 2014;5:1-41. doi: 10.1007/s13300-014-00613.

4. Tertti K, Ekblad U, Koskinen P, Vahlberg T, Rönnemaa T. Metformin vs. insulin in gestational diabetes. A randomized study characterizing metformin patients needing additional insulin. Diabetes Obes Metab. 2013;15:246-51. doi: 10.1111/ dom.12017.

5. Ponssen HH, Elte JW, Lehert P, Schouten JP, Bets D. Combined metformin and insulin therapy for patients with type 2 diabetes mellitus. Clin Ther. 2000;22:709-18.

6. Lashen $\mathrm{H}$. Role of metformin in the management of polycystic ovary syndrome. Ther Adv Endocrinol Metab. 2010;1:117-28.

7. Betônico CCR, Titan SMO, Correa-Giannella MLC, Nery M, Queiroz M. Management of diabetes mellitus in individuals with chronic kidney disease:therapeutic perspectives and glycemic control. Clinics. 2016;71:47-53.

8. Rojas LBA, Gomes MB. Metformin:an old but still the best treatment for type 2 diabetes. Diabetol Metab Syndr. 2013;5:6. doi: 10.1186/1758-5996-5-6.

9. Inzucchi SE, Lipska KJ, Mayo H, Bailey CJ, McGuire DK. Metformin in patients with type 2 diabetes and kidney disease:A systematic review. JAMA. 2014;312:2668-75. doi: 10.1001/jama.2014.15298.

10. Kinsara AJ, Ismail YM. Metformin in heart failure patients. Indian Heart J. 2017.

11. Gong L, Goswami S, Giacomini KM, Altman RB, Klein TE. Metformin pathways: pharmacokinetics and pharmacodynamics. Pharmacogenet Genomics. 2012;22:820-7. doi: 10.1097/FPC.0b013e3283559b22.

12. Foretz M, Guigas B, Bertrand L, Pollak M, Viollet B. Metformin:from mechanisms of action to therapies. Cell Metab. 2014;20:953-66.

13. Amini FG, Rafieian-Kopaei M, Nematbakhsh M, Baradaran A, Nasri H. Ameliorative effects of metformin on renal histologic and biochemical alterations of gentamicin- induced renal toxicity in Wistar rats. J Res Med Sci. 2012;17:621-5.

14. Miller RA, Chu Q, Xie J, Foretz M, Viollet B, Birnbaum MJ. Biguanides suppress hepatic glucagon signalling by decreasing production of cyclic AMP. Nature. 2013;494:25660.

15. Lee H, Ko G. Effect of metformin on metabolic improvement and gut microbiota. Appl Environ Microbiol. 2014;80:593543 .

16. Zhou G, Myers R, Li Y, Chen Y, Shen X, Fenyk-Melody J, et al. Role of AMP-activated protein kinase in mechanism of metformin action. J Clin Invest. 2001;108:1167-74.

17. Lee JO, Lee SK, Kim JH, Kim N, You GY, Moon JW, et al. Metformin regulates glucose transporter 4 (GLUT4) translocation through AMP-activated protein kinase (AMPK)-mediated Cbl/CAP signaling in 3T3-L1 preadipocyte cells. J Biol Chem. 2012;287:44121-9.

18. Konopka AR, Esponda RR, Robinson MM, Johnson ML, Carter RE, Schiavon M, et al. Hyperglucagonemia mitigates the effect of metformin on glucose production in prediabetes. Cell Rep. 2016;15:1394-1400. doi: 10.1016/j. celrep.2016.04.024.

19. Collier CA, Bruce CR, Smith AC, Lopaschuk G, Dyck DJ. Metformin counters the insulin-induced suppression of fatty acid oxidation and stimulation of triacylglycerol storage in rodent skeletal muscle. Am J Physiol Endocrinol Metab. 2006;291:E182-9

20. Ikeda $\mathrm{T}$, Iwata $\mathrm{K}$, Murakami $\mathrm{H}$. Inhibitory effect of metformin on intestinal glucose absorption in the perfused rat intestine. Biochem Pharmacol. 2000;59:887-90.

21. Del Barco S, Vazquez-Martin A, Cufí S, Oliveras-Ferraros C, Bosch-Barrera J, Joven J, et al. Metformin:Multi-faceted protection against cancer. Oncotarget. 2011;2:896-917.

22. Xiao H, Zhang J, Xu Z, Feng Y, Zhang M, Liu J, et al. Metformin is a novel suppressor for transforming growth factor (TGF)- $\beta 1$. Sci Rep. 2016;6:28597. doi: 10.1038/ srep28597.

23. Bouchoucha M, Uzzan B, Cohen R. Metformin and digestive disorders. Diabetes Metab. 2011;37:90-6.

24. DeFronzo R, Fleming GA, Chen K, Bicsak TA. Metforminassociated lactic acidosis:Current perspectives on causes and risk. Metabolism. 2016;65:20-9. doi: 10.1016/j. metabol.2015.10.014.

25. Kirkman MS, Briscoe VJ, Clark N, Florez H, Haas LB, Halter JB, et al. Diabetes in older adults. Diabetes Care. 2012;35:2650-64.

26. Karimifar M, Aminorroaya A, Amini M, Mirfendereski T, Iraj B, Feizi A, et al. Effect of metformin on thyroid stimulating hormone and thyroid volume in patients with prediabetes:A randomized placebo-controlled clinical trial. J Res Med Sci. 2014;19:1019-26.

27. Cappelli C, Rotondi M, Pirola I, Agosti B, Formenti AM, De Cata $\mathrm{P}$, et al. Metformin-induced thyrotropin suppression is not associated with cardiac effects. Hormones. 2014;13:2528.

28. Lupoli R, Di Minno A, Tortora A, Ambrosino P, Lupoli GA, Di Minno MN. Effects of treatment with metformin on TSH levels:a meta-analysis of literature studies. J Clin Endocrinol Metab. 2014;99:E143-8.

29. Pham AQT. Drug-Induced Metabolic Acidosis. 2015;4: F1000 Faculty Rev-1460. doi: 10.12688/ f1000research.7006.1

30. Wills BK, Bryant SM, Buckley P, Seo B. Can acute overdose 
of metformin lead to lactic acidosis? Am J Emerg Med. 2010;28:857-61.

31. Runge S, Mayerle J, Warnke C, Robinson D, Roser M, Felix $\mathrm{SB}$, et al. Metformin-associated lactic acidosis in patients with renal impairment solely due to drug accumulation? Diabetes Obes Metab. 2008;10:91-3.

32. Jagia M, Taqi S, Hanafi M. Metformin poisoning:A complex presentation. Indian J Anaesth. 2011;55:190-2.

33. Kim MJ, Han JY, Shin JY, Kim SI, Lee JM, Hong S, et al. Metformin-associated lactic acidosis: predisposing factors and outcome. Endocrinol Metab. 2015;30:78-83.

34. Lee SY, Moon SJ, Kim EK, Seo HB, Yang EJ, Son HJ, et al. Metformin suppresses systemic autoimmunity in roquin(san/san) mice through Inhibiting B cell differentiation into plasma cells via regulation of AMPK/ mTOR/STAT3. J Immunol. 2017;198:2661-70.

35. Kopec KT, Kowalski MJ. Metformin-associated lactic acidosis (MALA): case files of the einstein medical center medical toxicology fellowship. J Med Toxicol. 2013;9:61-6.

36. Rojas LBA, Gomes MB. Metformin: an old but still the best treatment for type 2 diabetes. Diabetol Metab Syndr. 2013;5:6.

37. Shen Y, Miao N, Xu J, Gan X, Xu D, Zhou L, et al. Metformin prevents renal fibrosis in mice with unilateral ureteral obstruction and inhibits Ang II-Induced ECM production in renal fibroblasts. Int J Mol Sci. 2016;17. pii: E146. doi: 10.3390/ijms17020146.

38. Liu Y. Epithelial to mesenchymal transition in renal fibrogenesis:pathologic significance, molecular mechanism, and therapeutic intervention. J Am Soc Nephrol. 2004;15:112 .

39. Simon N, Hertig A. Alteration of fatty acid oxidation in tubular epithelial cells: from acute kidney injury to renal fibrogenesis. Front Med (Lausanne). 2015;2:52. doi: $10.3389 /$ fmed.2015.00052.

40. Ghigliotti G, Barisione C, Garibaldi S, Fabbi P, Brunelli C, Spallarossa $\mathrm{P}$, et al. Adipose tissue immune response:novel triggers and consequences for chronic inflammatory conditions. Inflammation. 2014;37:1337-53.

41. Mummidi S, Das NA, Carpenter AJ, Kandikattu H, Krenz M, Siebenlist U, et al. Metformin inhibits aldosterone-induced cardiac fibroblast activation, migration and proliferation in vitro, and reverses aldosterone+salt-induced cardiac fibrosis in vivo. J Mol Cell Cardiol. 2016;98:95-102. doi: 10.1016/j.yjmcc.2016.07.006

42. Saeedi Saravi SS, Hasanvand A, Shahkarami K, Dehpour AR. The protective potential of metformin against acetaminophen-induced hepatotoxicity in BALB/C mice. Pharm Biol. 2016;54:2830-7. doi: $10.1080 / 13880209.2016 .1185633$.

43. Arbeláez-Quintero I, Palacios M. To use or not to use metformin in cerebral ischemia: a review of the application of metformin in stroke rodents. Stroke Res Treat. 2017;2017:9756429.

44. Kumar P, Kale R, Baquer N. Modulation of metabolic parameters and antioxidant enzymes in diabetic ageing female rat brains: beneficial role of metformin. Endocrine Abstracts. 2015. doi: 10.1530/endoabs.37.EP398.

45. Yang X, Ding H, Qin Z, Zhang C, Qi S, Zhang H, et al. Metformin prevents renal stone formation through an antioxidant mechanism in vitro and in vivo. Oxid Med Cell Longev. 2016;2016:4156075. doi: 10.1155/2016/4156075.

46. Jin J, Gu H, Anders NM, Ren T, Jiang M, Tao M, et al. Metformin protects cells from mutant huntingtin toxicity through activation of AMPK and modulation of mitochondrial mynamics. Neuromolecular Med. 2016;18:581-92.

47. Lin $\mathrm{CH}$, Cheng YC, Nicol CJ, Lin $\mathrm{KH}$, Yen $\mathrm{CH}$, Chiang MC. Activation of AMPK is neuroprotective in the oxidative stress by advanced glycosylation end products in human neural stem cells. Exp Cell Res. 2017;359:367-373. doi: 10.1016/j.yexcr.2017.08.019.

48. Bibi F, Ullah I, Kim MO, Naseer MI. Metformin attenuate PTZ-induced apoptotic neurodegeneration in human cortical neuronal cells. Pak J Med Sci. 2017;33:581-5.

49. Lee JY, Lee SH, Chang JW, Song JJ, Jung HH, Im GJ. Protective effect of metformin on gentamicin-induced vestibulotoxicity in rat primary cell culture. Clin Exp Otorhinolaryngol. 2014;7:286-94.

50. Dowling Ryan JO, Lam S, Bassi C, Mouaaz S, Aman A, Kiyota $\mathrm{T}$, et al. Metformin pharmacokinetics in mouse tumors:implications for human therapy. Cell Metab. 2016;23:567-8. doi: 10.1016/j.cmet.2016.03.006

51. Franciosi M, Lucisano G, Lapice E, Strippoli GFM, Pellegrini F, Nicolucci A. Metformin therapy and risk of cancer in patients with type 2 diabetes:systematic review. PLOS One. 2013;8:e71583. doi: 10.1371/journal.pone.0071583

Copyright $\odot 2018$ The Author(s); Published by Society of Diabetic Nephropathy Prevention. This is an open-access article distributed under the terms of the Creative Commons Attribution License (http://creativecommons.org/licenses/by/4.0), which permits unrestricted use, distribution, and reproduction in any medium, provided the original work is properly cited. 